RASĀYAN J. Chem.

Vol. 12 | No. 4 |1774 - 1782| October - December | 2019

ISSN: 0974-1496 | e-ISSN: 0976-0083 | CODEN: RJCABP

RJC

http://www.rasayanjournal.com

http://www.rasayanjournal.co.in

\title{
MOLECULAR INTERACTIONS IN BINARY LIQUID MIXTURES CONTAINING BENZYL BENZOATE
}

\author{
A.Nagarjuna ${ }^{1, *}$, K.V.Yamini Kanth ${ }^{2}$, G. Balaji Prakash ${ }^{3}$ and Debashis Das ${ }^{4}$ \\ ${ }^{1}$ Research Scholar, Department of Physics, Koneru Lakshmaiah Education Foundation, \\ Vaddeswaram, A.P, India \\ ${ }^{2}$ Department of Science, Jain International School, Aurangabad, Maharashtra-431001, India \\ ${ }^{3}$ Department of Mathematics, Koneru Lakshmaiah Education Foundation, Vaddeswaram, \\ A.P, India \\ ${ }^{4}$ Department of Chemistry, Dinhata College, Cooch Behar Panchanan Barma University, \\ Dinhata, 736135, W. B, India \\ *E-mail:ayachitulanagarjuna@gmail.com
}

\begin{abstract}
Speeds of sound, densities and viscosities of the binary mixture of Benzyl benzoate with mole fractions of amides Formamide (FA), N-Methyl formamide (NMF) and Di methyl formamide (DMF) have been estimated utilizing the standard strategies at $303.15,308.15$ and $313.15 \mathrm{~K}$. From these deliberate values, different thermo-dynamic parameters such as isentropic compressibility $\left(\mathrm{K}_{\mathrm{s}}\right)$, intermolecular free length $\left(\mathrm{L}_{\mathrm{f}}\right)$, molar volume $\left(\mathrm{V}_{\mathrm{m}}\right)$, Gibbs free energy $(\Delta \mathrm{G})$, enthalpy $(\mathrm{H})$ and their excess properties were determined. The figured qualities have been fitted to the Redlich-Kister type polynomial condition utilizing least squares technique to assess the twofold coefficients and standard deviations.
\end{abstract}

Keywords: Speed of Sound, Density, Molar Volume, Free Length, R-K polynomial.

(c) RASĀYAN. All rights reserved

\section{INTRODUCTION}

Changes in physicochemical properties of fluid mixtures with mole fractions and temperatures are important for understanding their thermodynamic behaviour. Amides are very interesting compounds as they possess the very common in nature - $\mathrm{CO}-\mathrm{NH}$ - peptide bond having great importance in molecular biology. Another important application of amides is that they can act as oxygen and /or nitrogen donors and can be used as extractant carriers for numerous radioactive elements. On the other hand, Benzyl Benzoate is an anti-parasitic insecticide, a plasticizer in cellulose, a food additive and fixative in fragrances and used for killing the mites responsible for scabies. ${ }^{1,2}$ So the thermo physical study of esters as one of the components in the binary system is of increasing interest due to their wide range of applications in flavouring, perfumery, artificial essences, cosmetics and medicines. Benzyl benzoate (BB) is a non polar aprotic solvent having low dipole moment $2.06 \mathrm{D}$ and dielectric constant 4.90 respectively. Amide mainly consists of the chain-like hydrogen-bonded structure by combining through $-\mathrm{NH}_{2} \ldots \ldots \mathrm{O}=$ $\mathrm{CH}$ - interactions. ${ }^{3}$ As abiding the discussion on amides and benzyl benzoate the experimental results of measured density $(\rho)$, viscosity $(\eta)$ and speed of sound $(U)$ values were used to calculate the excess properties as well as fitted to the reduced Redlich-Kister (R-K) equations, through the Legendre polynomials, and are interpreted in terms of molecular interactions and structural effects. A brief survey of literature has shown that the trends found in our results are in good agreement with the results reported by earlier workers. ${ }^{4-8}$ having similarity in the components of the system. Additionally, FTIR analysis explains the shifting of principal bands also supports the breaking as well as forming of new H-bonding between the components for the binary system of Benzyl benzoate with formamide, NMF and $\mathrm{DMF}^{9-14}$ at different mole fractions.

Rasayan J. Chem., 12(4), 1774-1782(2019)

http://dx.doi.org/10.31788/RJC.2019.1245469

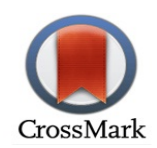


RASĀYAN J. Chem.

Vol. 12 | No. 4 |1774 - 1782| October - December | 2019

\section{EXPERIMENTAL}

The samples were prepared very soon to start the experiment with the assistance of mass disparity and uncertainty in the mole fraction was projected to be less than \pm 0.0001 . The purity analysis of substances was reported in Table-1.

Table-1: Purity Analysis

\begin{tabular}{|c|c|c|c|c|c|c|}
\hline Chemical Name & $\begin{array}{c}\text { CAS } \\
\text { Number }\end{array}$ & Source & $\begin{array}{c}\text { Initial } \\
\text { Mole } \\
\text { Fraction }\end{array}$ & $\begin{array}{l}\text { Purification } \\
\text { Method }\end{array}$ & $\begin{array}{c}\text { Final } \\
\text { Mole } \\
\text { Fraction }\end{array}$ & $\begin{array}{l}\text { Analysis } \\
\text { Method }\end{array}$ \\
\hline Benzyl benzoate & $120-51-4$ & \multirow{3}{*}{$\begin{array}{c}\text { Hi Media } \\
\text { Laboratories Pvt. } \\
\text { Ltd. Mumbai, India }\end{array}$} & 0.99 & Distillation & 0.995 & GLC \\
\hline Formamide & $75-12-7$ & & 0.99 & Distillation & 0.997 & GLC \\
\hline DMF & $68-12-2$ & & 0.99 & Distillation & 0.997 & GLC \\
\hline NMF & $123-39-7$ & $\begin{array}{l}\text { Tokyo Industries.co. } \\
\text { Ltd, Japan }\end{array}$ & 0.99 & Distillation & 0.997 & GLC \\
\hline
\end{tabular}

\section{GLC-Gas Liquid Chromatography}

Table-2: Comparison of Experimental Densities $(\rho)$, Viscosities $(\eta)$ and Speed of sound $(U)$ of pure liquids with literature values.

\begin{tabular}{|c|c|c|c|c|c|c|c|c|c|}
\hline \multirow[t]{2}{*}{ Liquid } & \multirow[t]{2}{*}{$\begin{array}{l}\text { Temp } \\
(\mathrm{K})\end{array}$} & \multicolumn{2}{|c|}{ Density $(\rho) \mathrm{kg} \mathrm{m}^{3}$} & \multicolumn{2}{|c|}{ Viscosity $(\eta) \mathrm{mPa} \mathrm{s}$} & \multicolumn{2}{|c|}{$\begin{array}{l}\text { Speed of sound }(\mathrm{U}) \\
\mathrm{m} \mathrm{s}^{-1}\end{array}$} & \multirow{2}{*}{$\begin{array}{l}C_{P} \\
\mathrm{~J} \mathrm{~K}^{-1} \mathrm{~mol}^{-1}\end{array}$} & \multirow{2}{*}{$\begin{array}{l}\grave{\alpha} \\
\mathrm{K} \mathrm{K}^{-1}\end{array}$} \\
\hline & & lit & expt & lit & expt & lit & expt & & \\
\hline \multirow{3}{*}{$\begin{array}{l}\text { Benzyl } \\
\text { benzoate }\end{array}$} & 303.15 & $1.1193^{\mathrm{a}}$ & 1.1196 & $6.532^{\mathrm{a}}$ & 6.536 & $1506.0^{\mathrm{a}}$ & 1504.8 & $215.92^{\mathrm{g}}$ & $0.9966^{\mathrm{i}}$ \\
\hline & 308.15 & $1.1145^{b}$ & 1.1144 & $6.261^{b}$ & 6.342 & $1493.1^{b}$ & 1492.6 & $223.60^{\mathrm{g}}$ & $0.9931^{1}$ \\
\hline & 313.15 & $1.1097^{\mathrm{a}}$ & 1.1098 & $5.021^{\mathrm{a}}$ & 5.045 & $1471.4^{\mathrm{a}}$ & 1474.8 & $231.52^{\mathrm{g}}$ & $1.0036^{1}$ \\
\hline \multirow[t]{3}{*}{ Formamide } & 303.15 & $1.1257^{\mathrm{c}}$ & 1.1241 & $2.877^{\mathrm{c}}$ & 2.782 & $1588.0^{\mathrm{c}}$ & 1582.6 & $107.11^{\mathrm{h}}$ & $0.9967^{\mathrm{i}}$ \\
\hline & 308.15 & $1.1198^{\mathrm{d}}$ & 1.1189 & $2.500^{\mathrm{d}}$ & 2.468 & $1577.2^{\mathrm{d}}$ & 1580.4 & $105.20^{\mathrm{h}}$ & $0.9961^{\mathrm{i}}$ \\
\hline & 313.15 & $1.1183^{\mathrm{c}}$ & 1.1174 & $2.273^{\mathrm{c}}$ & 2.225 & $1568.0^{c}$ & 1574.0 & $108.56^{\mathrm{h}}$ & $0.9998^{1}$ \\
\hline \multirow[t]{3}{*}{ NMF } & 303.15 & $0.9946^{\mathrm{e}}$ & 0.9934 & $1.585^{\mathrm{e}}$ & 1.563 & $1408.5^{\mathrm{e}}$ & 1408.2 & $124.95^{\mathrm{h}}$ & $0.9989^{1}$ \\
\hline & 308.15 & $0.9903^{\mathrm{e}}$ & 0.9908 & $1.462^{\mathrm{e}}$ & 1.478 & $1400.6^{\mathrm{e}}$ & 1402.6 & $126.05^{\mathrm{h}}$ & $0.9960^{1}$ \\
\hline & 313.15 & $0.9861^{\mathrm{e}}$ & 0.9855 & $1.352^{\mathrm{e}}$ & 1.383 & $1382.2^{\mathrm{e}}$ & 1392.2 & $129.47^{\mathrm{h}}$ & $1.0047^{1}$ \\
\hline \multirow[t]{3}{*}{$\overline{\mathrm{DMF}}$} & 303.15 & $0.9476^{\mathrm{f}}$ & 0.9462 & $0.767^{\mathrm{f}}$ & 0.772 & $1459.6^{\mathrm{f}}$ & 1452.2 & $152.00^{\mathrm{h}}$ & $1.0037^{1}$ \\
\hline & 308.15 & $0.9421^{\mathrm{f}}$ & 0.9417 & $0.726^{\mathrm{f}}$ & 0.735 & $1434.7^{\mathrm{f}}$ & 1428.8 & $153.02^{\mathrm{h}}$ & $1.0014^{1}$ \\
\hline & 313.15 & $0.9351^{\mathrm{f}}$ & 0.9333 & $0.679^{\mathrm{f}}$ & 0.688 & $1420.8^{f}$ & 1414.6 & $157.14^{\mathrm{h}}$ & $1.0020^{\mathrm{i}}$ \\
\hline
\end{tabular}

Standard uncertainties ' $\mathrm{u}$ ' are $\mathrm{u}\left(\mathrm{X}_{1}+\mathrm{X}_{2}\right)=0.0001, \mathrm{u}(\rho)=0.01 \mathrm{~kg} \mathrm{~m}^{3}, \mathrm{u}(\eta)=0.001 \mathrm{mPa}, \mathrm{u}(\mathrm{U})=0.56 \mathrm{~m} \mathrm{~s}^{-1}$

${ }^{\mathrm{a}}$ Reference[9] ${ }^{\mathrm{b}}$ Reference[10] ${ }^{\mathrm{c}}$ Reference[11] ${ }^{\mathrm{d}}$ Reference[12] ${ }^{\mathrm{e}}$ Reference[13]

${ }^{\mathrm{f}}$ Reference[14] ${ }^{\mathrm{g}}$ Estimated from NIST web book ${ }^{\mathrm{h}}$ Reference[23] ${ }^{\mathrm{i}}$ From density data

Interferometer (M-81S, M/s Mittal Enterprises, New Delhi, India) may use to measure the speed of sound at $2 \mathrm{MHz}$ frequency with an exactness of $\pm 0.1 \mathrm{~m} \cdot \mathrm{s}^{-1}$ for benzyl benzoate with formamide, NMF and DMF and uncertainty in the speed of sound to be established by $\pm 0.56 \mathrm{~m} \cdot \mathrm{s}^{-1}$. The density of mixtures was measured with standard technique (specific gravity bottle) and uncertainty in density is $\pm 0.01 \mathrm{~kg} \mathrm{~m}^{3}$. The viscosities were measured with Ostwald viscometer. The viscometer was calibrated at different temperatures using redistilled water. The flow time has been measured after the attainment of bath temperature by each pure compound and mixtures. The flow time has been measured with an electronic stop watch (Winner digital stopwatch W-999, Ravi scientific industries, New Delhi, India) with a precision of $\pm 0.01 \mathrm{~s}$. The uncertainty in viscosity measurement is up to $\pm 0.001 \mathrm{mPa}$ s. For all the measurements, the temperature was maintained by circulating water from an electronically controlled 
RASĀYAN J. Chem.

Vol. 12 | No. 4 |1774 - 1782| October - December | 2019

thermostatic bath (M/s Mittal Enterprises, New Delhi) with a precision of $\pm 0.01 \mathrm{~K}$. The infrared spectra for all systems have been recorded using (Alpha-2, M/S Bruker, Germany) at Chalapathi Institute of Pharmaceutical Sciences -drug testing Lab, Guntur, India. The comparison of experimental densities ( $\rho$ ), viscosities $(\eta)$ and speed of sounds $(\mathrm{U})$ of pure liquids with literature values are given in Table-2.

\section{RESULTS AND DISCUSSION}

Excess thermodynamic properties: The values of excess properties with mole fraction for the studied binary system at three different temperatures have been calculated by using equations (1) to (6) and are presented in Figures (1) to (5).

Excess isentropic compressibility $K_{s}^{E}=K_{s}-K_{s}^{i d}, K_{s}=\frac{1}{\rho \cdot U^{2}} \mathrm{Kg}^{-1} \mathrm{~ms}^{-2}$

Where $\mathrm{K}_{\mathrm{s}}$ id is the ideal isentropic compressibility relation recommended by Benson \& Kiyohara. ${ }^{15}$

$K_{s}^{i d}=\sum \emptyset \mathrm{i}\left\{K s, i^{0+\frac{T V i^{0}\left(\grave{\alpha i}^{0}\right) 2}{C p, i^{0}}}\right\}-T\left(\sum X i V i^{\mathrm{o}}\right)\left(\frac{\sum \varnothing \mathrm{i} \dot{\alpha} \mathrm{i}^{\mathrm{o}, 2}}{\sum X i C p, i^{\mathrm{o}}}\right)$

In which $K_{s i}{ }^{o}, V^{i} o, \grave{\alpha}_{i}^{o}, C_{p, j}{ }^{o}$ are the isentropic compressibility, molar volume, isobaric thermal expansion coefficient and molar isobaric heat capacity of pure component $i$, T represents temperature and $\phi_{i}$ is volume fraction.

Excess molar volume $V_{m}{ }^{E}=X_{1} M_{1}+X_{2} M_{2} / \rho-\left(X_{1} M_{1} / \rho_{1}+X_{2} M_{2} / \rho_{2}\right)$

Excess free length

$$
L_{f}^{E}=L_{f^{-}} K_{T}\left(K_{s}^{i d}\right)^{1 / 2} L_{f}=K_{T} \sqrt{K s} \quad \mathrm{~A}^{\mathrm{o}}
$$

$\mathrm{K}_{\mathrm{T}}$ represent a temperature dependent constant where $K_{T}=(91.368+0.3565 T) * 10^{-8}$

Excess Gibb's free energy $\quad \Delta G^{* E}=R T\left[\ln \left(\eta V / \eta_{2} V_{2}\right)-X_{1} \ln \left(\eta_{1} V_{1} / \eta_{2} V_{2}\right)\right]$

Where $\mathrm{R}$ represents gas constant, $\mathrm{T}$ is absolute temperature

Excess Enthalpy $\quad H^{E}=H-\left(X_{1} H_{1}+X_{2} H_{2}\right) H=\pi_{i .} V$ J. $\mathrm{mol}^{-1}$

Where internal pressure $\pi_{\mathrm{i}}=\mathrm{bRT}\left[\frac{K \eta}{U}\right]^{1 / 2}\left[\frac{\rho 2 / 3}{M e f f 7 / 6}\right] \mathrm{Pa}$

Where $H$ represents the calculated value of enthalpy, $V$ is the molar volume, $\eta$ and $\rho$ represent obtained viscosity and density for the mixture and $H_{1}, H_{2}$ represents enthalpy $X_{1}, X_{2}$ represents mole fractions $\rho_{1}, \rho_{2}$ be the densities $\eta_{1}, \eta_{2}$ represents viscosities $V_{1}, V_{2}$ represents molar volumes and $M_{1}, M_{2}$ represents molecular weights of pure components 1 and 2, respectively. $b$ stands for the cubic packing factor which is assumed to binary liquids, $K$ is temperature independent constant, $R$ is the gas constant and $T$ is the absolute temperature of binary mixtures.

The observed values of all the excess properties can are explained the chemical or specific interactions result due to forming and/or breaking of hydrogen bonds and other complex-forming interactions and the geometrical effect allowing the molecule of smaller size to fit into the other's structure that makes the negative values of $L_{f}^{E}$ and $K_{s}^{E}$. Addition of BB with FA induces a gradual dissociation of hydrogen bonds in the FA molecule. At the same time, there is also the possibility of forming hydrogen bonds between FA and $\mathrm{BB}$ because FA possesses three hydrogen-bond donors in addition to a proton acceptor group $\mathrm{C}=\mathrm{O}$. The positive values of $V^{E}, \Delta G^{E}$ and $H^{E}$ over the whole composition range for the BB + FA,NMF and DMF mixture may be due to the predominance of breaking up of the hydrogen-bonded structures of the pure amides over the formation of (weak) hydrogen bonding between $\mathrm{BB}$ and amide molecules into the voids created by the bigger BB molecules.

The values of $K_{s}^{E}$ being negative for mixtures of BB with FA, NMA and DMF over the whole composition range, suggest that the interactions between $\mathrm{BB}$ and substituted amides are stronger than $\mathrm{BB}-\mathrm{BB}$ or amide-amide interactions. This finding is in accordance with a view proposed by Fort and 1776 
RASĀYAN J. Chem.

Moore. ${ }^{16}$ The strength of the interaction between $\mathrm{BB}$ and the substituted amide molecules seems to be strongly dependent on the positions of the methyl groups in the amide molecules. The substituted amide molecules in their pure state have lesser H-bonding network than primary amides. Mixing BB with substituted amides may induce the formation of a (new) hydrogen bond between the hydrogen atom of the amides with the carbonyl group of the ester and vice versa. Moreover, there may be a possibility of weak $\pi \ldots . . \mathrm{H}$ bonding between $\pi$-electrons of the benzene ring of BB and the $\mathrm{H}$-atom of substituted amide molecule as may be found in the recent studies of Rodham et .al ${ }^{17}$ and Larsen and co-workers ${ }^{18}$ in which they have been reported the existence of weak $\pi \ldots . \mathrm{H}$ bonding between the $\pi$-electrons of the benzene ring and the hydrogen atoms of ammonia and that of the $-\mathrm{OH}$ group of tert-butyl alcohol. This leads to the negative values of $K_{s}^{E}$ and $L_{f}^{E}$ in case of mixture of BB with substituted amides. The intermolecular free length is the distance between the surfaces of the neighbouring molecules. The variation of Speed of sound in a solution depends upon the increase or decrease of intermolecular free length after mixing the components. The interdependence of intermolecular free length and speed of sound was evolved from a model for sound propagation proposed by Kincaid and Eyring. ${ }^{19}$ The speed of sound for form amide mixtures found to be decreased with the mole fraction of $\mathrm{BB}$ whereas for the substituted amides it increases with the mole fraction of $\mathrm{BB}$ at three different temperatures. This effect shows the positive/negative deviation of intermolecular free length $L_{f}^{E}$ for formamide and other substituted amides and is useful to assess the compactness in the liquid mixture. The rise in temperature makes the intermolecular free length to increase as expected due to thermal expansion of the liquid medium. Another thermodynamic function, which has also been investigated, is the excess molar free energy of activation of flow $\left(\Delta G^{E}\right)$. According to Reed and Taylor ${ }^{20}$ and Meyers et. al ${ }^{21}$ the parameters may be considered as a reliable measure to detect the nature of interactions between unlike molecules. In all the present systems the $\Delta G^{E}$ values are found to be positive at all the compositions over the entire range of temperatures indicates the presence of specific interaction between the unlike components which is maximum for $\mathrm{BB}+\mathrm{FA} / \mathrm{DMF} / \mathrm{NMF}$ due to the possibility of $\mathrm{H}$-bonding as well as dipole and induced dipole interactions.

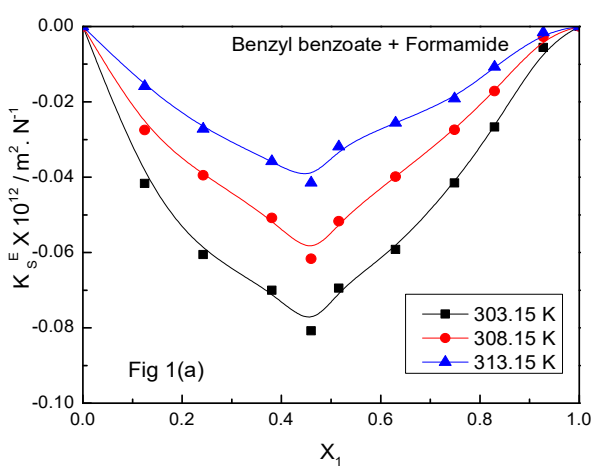

(A)

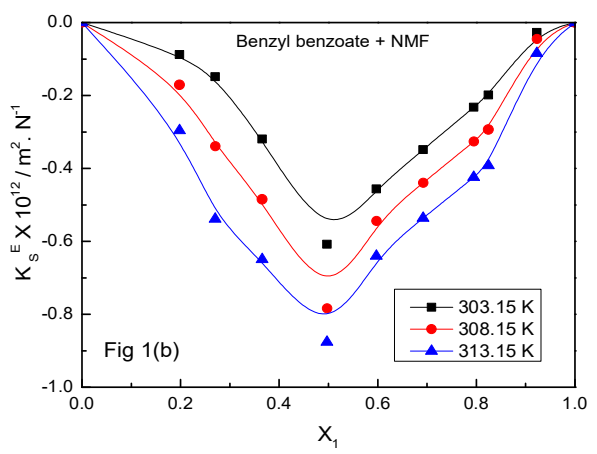

(C)

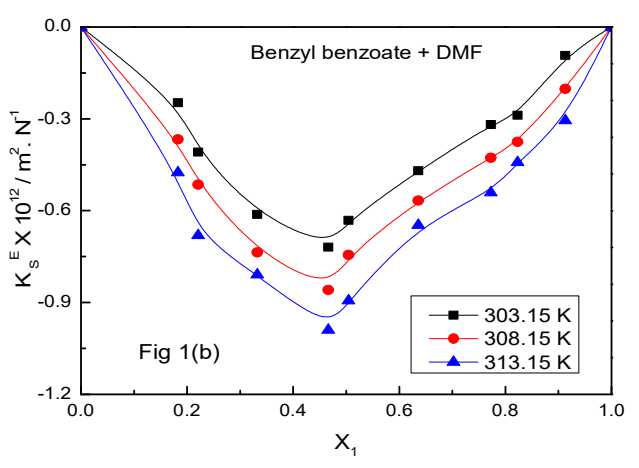

(B)

Fig.-1(A-C): Variation of Excess isentropic Compressibility with respect to mole fraction of Benzyl benzoate + Formamide/DMF/NMF at three different temperatures 
RASĀYAN J. Chem.

Vol. 12 | No. 4 |1774 - 1782 | October - December | 2019

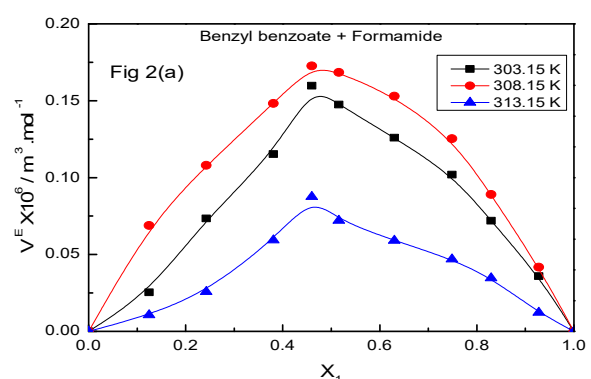

(A)

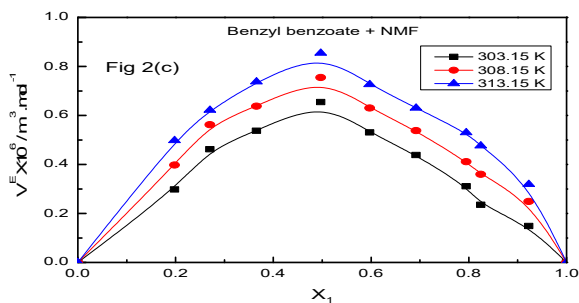

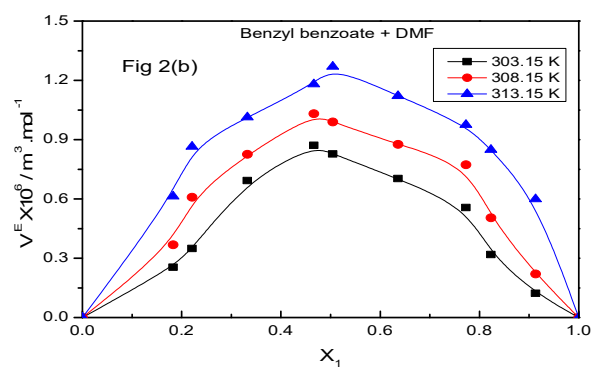

(B)

Fig.-2(A-C): Variation of Excess molar Volume with respect to mole fraction of Benzyl benzoate + Formamide/ DMF / NMF at three different temperatures

(C)

Next, Redlich- Kister type polynomial ${ }^{22}$ a nonlinear regression method is done by: $Y^{E}=X_{1}\left(1-X_{1}\right) \sum_{\mathrm{i}=1}^{\mathrm{n}} A_{i}\left(2 X_{1}-1\right)^{\mathrm{i}-1}$

Where $Y^{E}=K s^{E}, V^{E}, L_{f}^{E}$. The values of coefficient $A_{i}$ were determined by least square and reported in Table-3.

Standard deviation $(\sigma)$ written by $(\sigma)=\left[\Sigma_{\mathrm{i}=1}^{\mathrm{n}}\left(Y_{\text {exp }}^{E} Y_{\text {cal }}^{E}\right) / D-N\right]^{1 / 2}$

Where $D$ is the number of experimental data points and $N$ is the number of parameters.

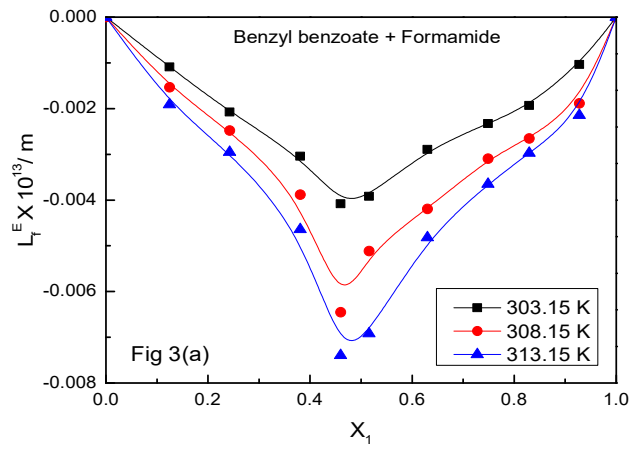

(A)

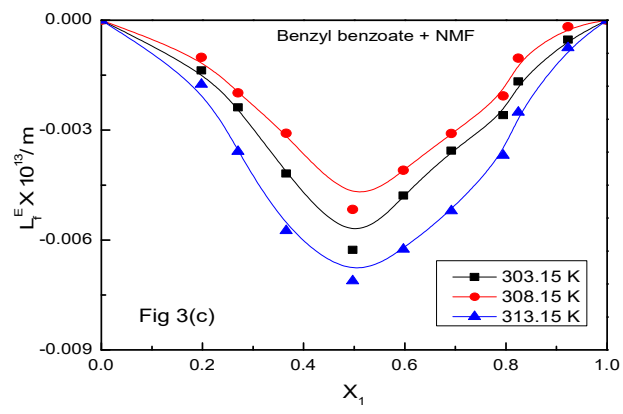

(C)

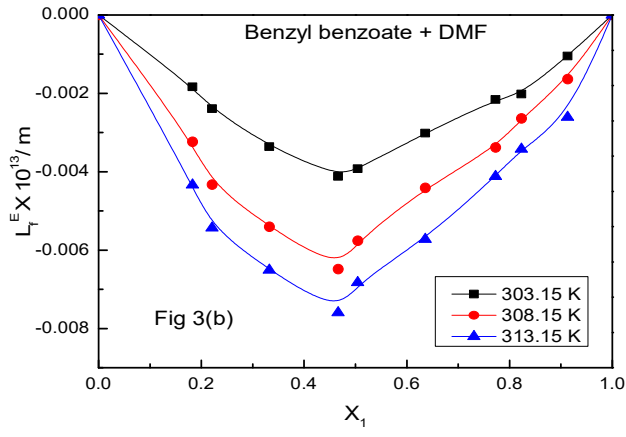

(B)

Fig.-3(A-C): Variation of Excess free length with respect to mole fraction of Benzyl benzoate + Formamide / DMF / NMF at three different temperatures 
RASĀYAN J. Chem.

Vol. 12 | No. 4 |1774 - 1782 | October - December | 2019

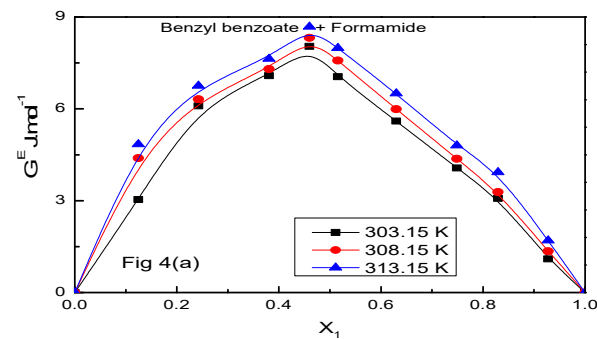

(A)

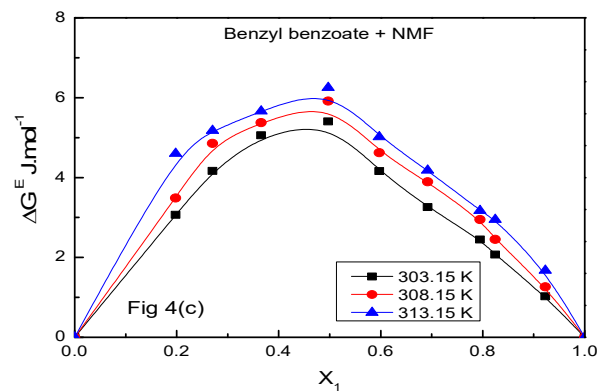

(C)

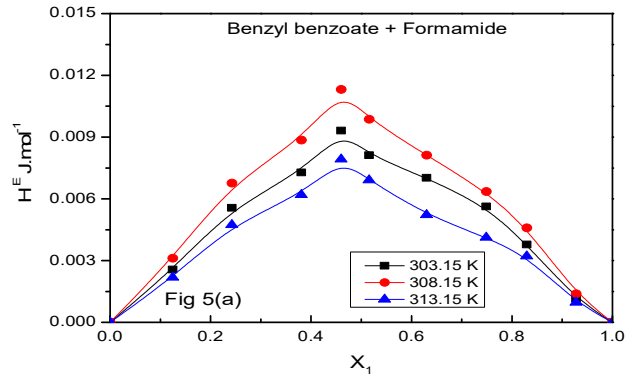

(A)

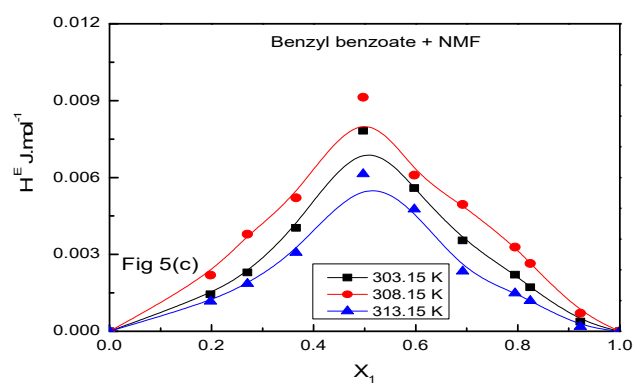

(C)

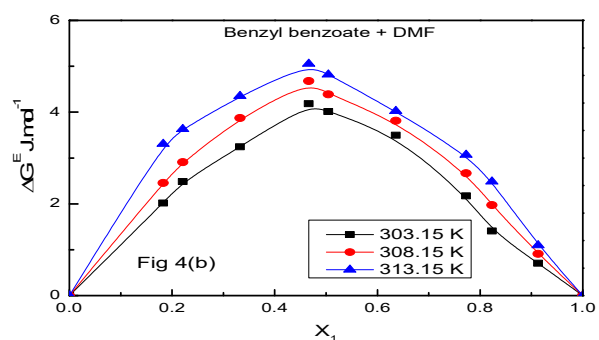

(B)

Fig.-4(A-C): Variation of Excess Gibbs free energy with respect to mole fraction of Benzyl benzoate + Formamide / DMF / NMF at three different temperatures

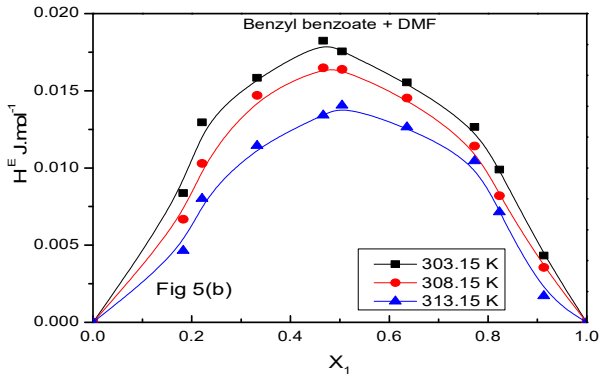

(B)

Fig.-5(a-c): Variation of Excess enthalpy with respect to mole fraction of Benzyl benzoate + Formamide / DMF / NMF at three different temperatures

Table-3: Parameters $\left(\mathrm{A}_{\mathrm{k}}\right)$ and Standard Deviation $(\sigma)$ for Benzyl benzoate with Formamide, DMF and NMF at $\mathrm{T}=$ $303.15 \mathrm{~K}, 308.15 \mathrm{~K}$ and $313.15 \mathrm{~K}$

\begin{tabular}{l|c|c|c|c|c|}
\hline Parameter & Temperature $(\mathrm{K})$ & $\mathrm{A} 0$ & $\mathrm{~A} 1$ & $\mathrm{~A} 2$ & $\sigma$ \\
\hline \multirow{3}{*}{$10^{12} \mathrm{~K}_{\mathrm{S}}{ }^{\mathrm{V}} /\left(\mathrm{m}^{2} \cdot \mathrm{N}^{-1}\right)$} & 303.15 & -0.2921 & 0.1350 & 0.0668 & 0.0029 \\
\cline { 2 - 6 } & 308.15 & -0.2131 & 0.0945 & 0.0969 & 0.0028 \\
\cline { 2 - 6 } & 313.15 & -0.1426 & 0.0605 & 0.0782 & 0.0020 \\
\hline
\end{tabular}


RASĀYAN J. Chem.

Vol. 12 | No. 4 |1774 - 1782| October - December | 2019

\begin{tabular}{|c|c|c|c|c|c|}
\hline \multirow{3}{*}{$10^{6} \mathrm{~V}^{\mathrm{E}} /\left(\mathrm{m}^{3} \cdot \mathrm{mol}^{-1}\right)$} & 303.15 & 0.5773 & 0.1577 & -0.3636 & 0.1378 \\
\hline & 308.15 & 0.6652 & 0.0289 & -0.0944 & 0.1436 \\
\hline & 313.15 & 0.2926 & 0.0798 & -0.2721 & 0.0668 \\
\hline \multirow{3}{*}{$10^{13} \mathrm{~L}_{\mathrm{f}}^{\mathrm{E}} /(\mathrm{m})$} & 303.15 & -0.0143 & -0.0019 & 0.0049 & 0.0458 \\
\hline & 308.15 & -0.0197 & -0.0042 & 0.0053 & 0.0310 \\
\hline & 313.15 & -0.0239 & -0.0043 & 0.0082 & 0.0188 \\
\hline \multirow{3}{*}{$\Delta \mathrm{G}^{\mathrm{E}} /\left(\mathrm{J} \cdot \mathrm{mol}^{-1}\right)$} & 303.15 & 28.6395 & -8.9965 & -7.6609 & 4.7352 \\
\hline & 308.15 & 29.3934 & -12.1845 & 1.1884 & 5.0328 \\
\hline & 313.15 & 30.8436 & -11.6963 & 6.2391 & 5.3669 \\
\hline \multirow{3}{*}{$\mathrm{H}^{\mathrm{E}} /\left(\mathrm{J} \cdot \mathrm{mol}^{-1}\right)$} & 303.15 & 0.0339 & -0.0010 & -0.0187 & 0.0533 \\
\hline & 308.15 & 0.0405 & -0.0024 & -0.0223 & 0.0404 \\
\hline & 313.15 & 0.0278 & -0.0026 & -0.0148 & 0.0269 \\
\hline \multicolumn{6}{|c|}{ Benzyl benzoate + DMF } \\
\hline \multirow{3}{*}{$10^{12} \mathrm{~K}_{\mathrm{S}}^{\mathrm{E}} /\left(\mathrm{m}^{2} \cdot \mathrm{N}^{-1}\right)$} & 303.15 & -2.6278 & 0.2923 & 1.8532 & 0.0431 \\
\hline & 308.15 & -3.0613 & 0.3084 & 0.9877 & 0.0498 \\
\hline & 313.15 & -3.4820 & 0.4105 & 0.0953 & 0.0610 \\
\hline \multirow{3}{*}{$10^{6} \mathrm{~V}^{\mathrm{E}} /\left(\mathrm{m}^{3} \cdot \mathrm{mol}^{-1}\right)$} & 303.15 & 3.4327 & 0.5034 & -3.3120 & 0.8991 \\
\hline & 308.15 & 4.0993 & 0.5705 & -2.1330 & 1.1268 \\
\hline & 313.15 & 4.7453 & 1.0932 & 1.5322 & 1.4176 \\
\hline \multirow{3}{*}{$10^{13} \mathrm{~L}_{\mathrm{f}}^{\mathrm{E}} /(\mathrm{m})$} & 303.15 & -0.0153 & 0.0002 & 0.0052 & 0.3962 \\
\hline & 308.15 & -0.0232 & 0.0040 & 0.0041 & 0.4864 \\
\hline & 313.15 & -0.0273 & 0.0044 & -0.0032 & 0.5778 \\
\hline \multirow{3}{*}{$\Delta \mathrm{G}^{\mathrm{E}} /\left(\mathrm{J} \cdot \mathrm{mol}^{-1}\right)$} & 303.15 & 16.1045 & -1.8280 & -9.7901 & 2.8781 \\
\hline & 308.15 & 17.9153 & -1.9977 & -6.9849 & 3.3327 \\
\hline & 313.15 & 19.2969 & -4.0274 & -1.0225 & 3.8062 \\
\hline \multirow{3}{*}{$\mathrm{H}^{\mathrm{E}} /\left(\mathrm{J} \cdot \mathrm{mol}^{-1}\right)$} & 303.15 & 0.0724 & 0.0003 & -0.0181 & 0.4102 \\
\hline & 308.15 & 0.0673 & 0.0040 & -0.0331 & 0.5007 \\
\hline & 313.15 & 0.0578 & 0.0080 & -0.0421 & 0.5910 \\
\hline \multicolumn{6}{|c|}{ Benzyl benzoate + NMF } \\
\hline \multirow{3}{*}{$10^{12} \mathrm{~K}_{\mathrm{S}}^{\mathrm{E}} /\left(\mathrm{m}^{2} \cdot \mathrm{N}^{-1}\right)$} & 303.15 & -2.0022 & -0.8225 & 3.1485 & 0.0409 \\
\hline & 308.15 & -2.6173 & -0.5773 & 3.1322 & 0.0526 \\
\hline & 313.15 & -3.1030 & -0.2168 & 2.3809 & 0.0532 \\
\hline \multirow{3}{*}{$10^{6} \mathrm{~V}^{\mathrm{E}} /\left(\mathrm{m}^{3} \cdot \mathrm{mol}^{-1}\right)$} & 303.15 & 2.3712 & -0.1227 & -1.0137 & 0.6402 \\
\hline & 308.15 & 2.7109 & -0.0338 & 0.0471 & 0.8217 \\
\hline & 313.15 & 3.0296 & 0.1104 & 1.0045 & 0.9956 \\
\hline \multirow{3}{*}{$10^{13} \mathrm{~L}_{\mathrm{f}}^{\mathrm{E}} /(\mathrm{m})$} & 303.15 & -0.0215 & -0.0047 & 0.0284 & 0.2708 \\
\hline & 308.15 & -0.0181 & -0.0039 & 0.0276 & 0.3679 \\
\hline & 313.15 & -0.0276 & -0.0064 & 0.0318 & 0.4595 \\
\hline \multirow{3}{*}{$\Delta \mathrm{G}^{\mathrm{E}} /\left(\mathrm{J} \cdot \mathrm{mol}^{-1}\right)$} & 303.15 & 19.7545 & -4.9526 & -5.2590 & 3.4312 \\
\hline & 308.15 & 21.7670 & -4.9848 & -2.8422 & 3.9231 \\
\hline & 313.15 & 22.5661 & -6.9109 & 5.7353 & 4.3637 \\
\hline \multirow{3}{*}{$\mathrm{H}^{\mathrm{E}} /\left(\mathrm{J} \cdot \mathrm{mol}^{-1}\right)$} & 303.15 & 0.0245 & 0.0053 & -0.0385 & 0.2770 \\
\hline & 308.15 & 0.0293 & 0.0048 & -0.0354 & 0.3745 \\
\hline & 313.15 & 0.0193 & 0.0031 & -0.0322 & 0.4660 \\
\hline
\end{tabular}

\section{FTIR Spectra}

The observed principal bands are listed in Table-4. Partial band assignments of the solvent mixtures by comparing with the pure solvents have been made and are discussed accordingly. The main absorptions bands displayed by the esters are due to $\mathrm{C}=\mathrm{O}$ (stretching) and $\mathrm{C}-\mathrm{O}$ (stretching) and amides are due to $\mathrm{C}=\mathrm{O}$ (stretching) and $\mathrm{N}-\mathrm{H}$ (stretching) vibrations. The shifting of ester $\mathrm{C}=\mathrm{O}$ (stretching) frequency of pure Benzyl Benzoate in the solvent mixtures with different amides may be due to the formation of hydrogen bonding between the unlike components.

The FT-IR spectra of these three mixtures with various compositions indicate that there are some variations in the peaks with compositions especially $30 \% \mathrm{BB}$ with $70 \%$ FA then the other two compositions for $\mathrm{BB}+\mathrm{FA}$ mixtures but for the other two mixtures there are no variations of peaks with 
RASĀYAN J. Chem.

Vol. 12 | No. 4 |1774 - 1782| October - December | 2019

respect to compositions. It is due to the dissociations of intra or inter molecular $\mathrm{H}$ - bonding of FA molecules or formation of the same between BB and FA molecules. The absent of shifting of peaks with variations of compositions of NMF and DMF in their mixtures ruled out the possibility of formation of intermolecular $\mathrm{H}$ - bonding between the unlike molecules.

Table-4: Characteristic FT-IR Absorption Frequencies of Functional Groups in $\mathrm{cm}^{-1 \mathrm{a}}$

\begin{tabular}{l|l|l|l|l|l|l|l|l}
\hline S.No. & Functional & \multicolumn{3}{|c|}{ Pure Solvent } & \multicolumn{3}{l}{ Solvent Mixtures } \\
\cline { 3 - 8 } & Group & BB & FA & NMF & DMF & BB+FA & BB+NMF & BB+DMF \\
\hline 1 & $\begin{array}{l}\text { Ester C=O } \\
\text { (stretching) }\end{array}$ & $1638(\mathrm{~s})$ & & & & $1714(\mathrm{~s})$ & $1717(\mathrm{~m})$ & $1717(\mathrm{~m})$ \\
\hline 2 & $\begin{array}{l}\text { Ester C-O } \\
\text { (stretching) }\end{array}$ & $1261(\mathrm{~s})$ & & & & $1265(\mathrm{~s})$ & $1269(\mathrm{vs})$ & $1269(\mathrm{vs})$ \\
\hline 3 & $\begin{array}{l}\text { Amide C=O } \\
\text { (stretching) }\end{array}$ & & $1682(\mathrm{vs})$ & $1664(\mathrm{vs})$ & $1669(\mathrm{vs})$ & $1601(\mathrm{w})$ & $1657(\mathrm{vs})$ & $1667(\mathrm{vs})$ \\
\hline 4 & $\begin{array}{l}\text { Amide N-H } \\
\text { (Stretching) }\end{array}$ & & $3310(\mathrm{vs})$ & $3300(\mathrm{vs})$ & & $3065(\mathrm{vw})$ & $3299(\mathrm{~m})$ & \\
\hline
\end{tabular}

${ }^{\mathrm{a}} \mathrm{vs}=$ very strong, $\mathrm{s}=$ strong, $\mathrm{m}=$ medium, $\mathrm{w}=$ weak, $\mathrm{vw}=$ very weak

\section{CONCLUSION}

The experimental values are used to compute various excess thermo dynamic parameters and also compared with the theoretical values obtained from the literature. The excess values of enthalpy and molar volume are found to be positive and small for all the binary systems also the values of excess properties $\mathrm{K}_{\mathrm{s}}^{\mathrm{E}}$ and $\mathrm{L}_{\mathrm{f}}^{\mathrm{E}}$ are found to be negative for the mixture of BB with FA, NMF and DMF in the whole mole fraction range at the three different temperatures. The results can be explained by the breaking of the intra and inter molecular H-bonding present in the pure amides molecules and there may be some dipole induced dipole interactions present in all the mixtures especially between secondary amide and benzyl benzoate, which is supported by the greater value of the thermodynamic function excess Gibbs energy. Further the values of the excess parameters are fitted to the Redlich-Kister polynomial equation and the results are also presented. Moreover, FTIR analysis of the pure solvent and their mixtures are also reported where the principal bands of the esters and amides are assigned. The spectra of various compositions of each of the three mixtures are compiled and presented in three different figures to understand the shifting of peaks for variations in mole fractions. The shifting of the principal bands also supports the breaking as well as forming of new H-bonding between the components of the mixture.

\section{ACKNOWLEDGMENT}

Author A. Nagarjuna is thankful to his guide Dr. Shaik Babu, Asst. Professor, Department of physics (FIST-DST sponsored department), K L E F, Guntur for his valuable suggestions and discussions. Also thankful to Department of physics (FIST-DST sponsored department), K L E F, Deemed to be University Guntur, A.P, India to provide lab facility.

\section{REFERENCES}

1. J. Richardi, H. Krienke and P.H Fries, Chem. Phys. Let, 273, 115(1997), DOI:10.1016/S00092614(97)00588-5

2. W.V Steele, R.D Chirico, B. Cowell, S.E Knipmeyer and A. Nguyen, J. Chem. Eng. Data, 47, 667 (2002), DOI: $10.1021 / \mathrm{je} 0100847$

3. N. E Hill, Dielectric Behaviour of Biological Molecules in Solution. Clarendon Press: Oxford University Press, Oxford and London,p.16 (1978), DOI: 10.1016/0307-4412(79)90015-3

4. S. Suriya Shihab, K. Govinda Rao, M. Gnana Kiran, S. Babu and S.S Sastry, Rasayan. J. Chem, 10, (2017), DOI:10.7324/RJC.2017.1011552

5. S. Suriya Shihab, S. Babu and S. Sreeharisastry, Rasayan J. Chem, 9(4), 641 (2016).

6. A. Nagarjuna, S. Babu , K. Govinda Rao and T. Kalimulla, Asian J. Chem., 30, 2008(2018), DOI: 10.14233/ajchem.2018.21385 
RASĀYAN J. Chem.

Vol. 12 | No. 4 |1774 - 1782 | October - December | 2019

7. K. Govindarao and S. Babu ,Rasayan J. Chem, 12(3), 1110(2019), DOI: 10.31788/RJC.2019.1235285

8. H. Salhi, S. Babu, A. A Al-Arfaj, M.A Alkhaldi, N.O Alzamel, S. Akhtar and N.Ouerfelli, Rasayan.J. Chem., 9, 864(2016)

9. S.M Nayeem, S. Nyamathulla, I. Khan and D.K Rao, J. Mol. Liq, 218, 676(2016), DOI: 10.1016/j.molliq.2016.02.045

10. N.J Madhuri,P.S Naidu, J. Glory and K.R Prasad, E-J.Chem., 8, 457(2011), DOI: $10.1155 / 2011 / 464098$

11. W.E Acree, Phys. Chem. Liq, 51, 764 (2013), DOI:10.1080/00319104.2013.793600

12. P.K Pandey, A. Awasthi and A.Awasthi, J. Mol. Liq, 187, 343(2013), DOI:10.1016/j.molliq.2013.09.002

13. R. Balaji, M.G Sankar, M.C Sekhar and M.C. Shekar, Kar. Int. J. Mod. Sci, 2, 10(2016), DOI:10.1016/j.kijoms.2015.12.001

14. D.R Godhani, P.B Dobariya, A.M Sanghani and J.P Mehta, Arab. J.chem, 10, 422(2017), DOI: 10.1016/j.arabjc.2012.10.002

15. O. Kiyohara and G.C. Benson, J. Chem. Thermodyn, 11, 861 (1979), DOI:10.1016/00219614(79)90067-3

16. R.J Fort and W.R Moore,Trans. Faraday Soc. 61, 2102(1965), DOI:10.1039/tf9656102102

17. D.A Rodham, S. Suzuki, R.D Suenram, F.J Lovas, S. Dasgupta, W.A Goddard and G.A Blake, Nature, 362, 735 (1993), DOI:10.1038/362735a0

18. G. Larsen, Z.K Ismail, B. Herreros and R.D Parra, J. Phys. Chem. A, 102, 4734 (1998), DOI: $10.1021 /$ jp981091d

19. J.F Kincaid and H. Eyring, J. Chem. Phys., 6, 620 (1938), DOI:10.1063/1.1750134

20. T.M Reed III and T.E Taylor, J. Phys. Chem, 63, 58 (1959), DOI: 10.1021/j150571a016

21. R. Meyer, M. Meyer, J. Meyer and A. Peneloux, J.Chem. Phys., 62, 405(1971), DOI:10.1016/S0167$7322(00) 80001-\mathrm{X}$

22. O. Redlich and A.T Kister, Ind. Eng. Chem., 40, 345 (1948), DOI:10.1021/ie50458a036

23. R C Reid, J M Prausnitz, B E Poling, The Properties of Gases and Liquids, $5^{\text {th }}$ ed, McGraw Hill book company, New York(1987), DOI:10.1036/0070116822

[RJC-5469/2019] 